\title{
Atomic Level Tuning of the Catalytic Properties: Doping Effects of 25-Atom Bimetallic Nanoclusters on Styrene Oxidation
}

\author{
Gao $\mathrm{Li}^{\dagger}$ and Rongchao Jin* \\ Department of Chemistry, Carnegie Mellon University, Pittsburgh, Pennsylvania 15213, USA
}

\begin{abstract}
:
Atomically precise bimetallic $\mathrm{M}_{\mathrm{x}} \mathrm{Au}_{25-\mathrm{x}}(\mathrm{SR})_{18}\left(\mathrm{M}=\mathrm{Cu}\right.$ and $\left.\mathrm{Ag}, \mathrm{R}=\mathrm{CH}_{2} \mathrm{CH}_{2} \mathrm{Ph}\right)$ nanoclusters are investigated as oxide-supported catalysts for the catalytic oxidation of styrene. Their catalytic properties are compared with the case of homogold $\mathrm{Au}_{25}(\mathrm{SR})_{18}$ nanocluster. The oxide-supported $\mathrm{M}_{\mathrm{x}} \mathrm{Au}_{25-\mathrm{x}}(\mathrm{SR})_{18}$ catalysts give rise to $42-82 \%$ conversion of styrene at $70{ }^{\circ} \mathrm{C}$ using (diacetoxyiodo)benzene $\left(\mathrm{PhI}(\mathrm{OAc})_{2}\right)$ as the oxidant. The $\mathrm{Ag}$ and $\mathrm{Cu}$ dopants are found to modulate both the activity (i.e. conversion of styrene) and the selectivity to styrene epoxide or benzaldehyde (major products). The $\operatorname{Ag}_{\mathrm{x}} \mathrm{Au}_{25-\mathrm{x}}(\mathrm{SR})_{18}$ clusters exhibit higher activity and benzaldehyde selectivity than the homogold cluster, while the $\mathrm{Cu}_{\mathrm{x}} \mathrm{Au}_{25-\mathrm{x}}(\mathrm{SR})_{18}$ clusters primarily enhance the selectivity to benzaldehyde without significantly changing the activity. The results provide insights into the factors that influence the catalytic activity and selectivity in styrene oxidation.
\end{abstract}

Keywords: Gold nanoclusters, doping, silver, copper, catalytic oxidation

*To whom correspondence should be addressed. Email: rongchao@andrew.cmu.edu.

${ }^{\dagger}$ Current address: State Key Laboratory of Catalysis, Dalian Institute of Chemical Physics, Chinese Academy of Sciences, Dalian, Liaoning 126023, China.

(C) 2015. This manuscript version is made available under the Elsevier user license http://www.elsevier.com/open-access/userlicense/1.0/ 


\section{Instroduction}

Gold-based bimetallic nanocluster catalysts as well as homogold nanoclusters hold potential in a variety of reactions [1-4], such as catalytic oxidation reactions of $\mathrm{CO}$ [5,6], alcohols [7-9], and olefins [10-13] (e.g. propene and styrene). Recent advances in the synthesis of ligand-protected nanoclusters in solution phase have achieved atomic level control of the composition of gold-based bimetallic nanoclusters [14]. A notable example is the attainment of bimetallic $\mathrm{M}_{\mathrm{x}} \mathrm{Au}_{25-\mathrm{x}}(\mathrm{SR})_{18}$ nanoclusters $(\mathrm{M}=\mathrm{Ag}$ and $\mathrm{Cu}$ ) [15-17]. Although their structure is similar to that of the homogold $\mathrm{Au}_{25}(\mathrm{SR})_{18}$ nanocluster, the bimetallic nanoclusters exhibit different electronic properties due to the substitution of heteroatoms into the gold framework [14-17]. Such effects prompt us that the catalytic properties of bimetallic $\mathrm{M}_{\mathrm{x}} \mathrm{Au}_{25-\mathrm{x}}(\mathrm{SR})_{18}$ would also be changed compared to the $\mathrm{Au}_{25}(\mathrm{SR})_{18}$ nanocluster, albeit all of these clusters share the same atomic packing structure.

Previously Tsukuda and coworkers reported that the ligand-off $\operatorname{Pd}_{1} \mathrm{Au}_{24}$ nanoclusters on multiwalled carbon nanotubes gave rise to a much better catalytic activity than that of the ligand-off $\mathrm{Au}_{25}$ nanocluster in aerobic oxidation of benzyl alcohol to benzaldehyde [18]. Selective oxidation of organic compounds (e.g. alcohol and olefins) with environmentally friendly oxidants (e.g. oxygen, hydrogen peroxide, and (diacetoxyiodo)benzene) is an important direction in green organic catalytic chemistry $[19,20]$. Konishi et al. reported epoxidation of olefins catalyzed by a manganese-porphyrin complex with dodecanethiolate-protected metallic gold nanoclusters as a co-catalyst and iodosylbenzene (PhIO) as the oxidant [21]. In our previous work, we investigated the catalytic properties of monoplatinum-doped $\mathrm{Pt}_{1} \mathrm{Au}_{24}(\mathrm{SR})_{18} / \mathrm{TiO}_{2}$ using $\mathrm{PhI}(\mathrm{OAc})_{2}$ as oxidant in the oxidation of styrene [22]. The Pt-centered $\mathrm{Pt}_{1} \mathrm{Au}_{24}(\mathrm{SR})_{18}$ cluster showed much higher catalytic activity and selectivity for benzaldehyde than the $\mathrm{Au}_{25}(\mathrm{SR})_{18}$ cluster catalyst.

Herein, we are motivated to investigate the catalytic properties of copper and silver-doped nanoclusters. Compared to the mono-doping cases of $\mathrm{Pd}$ and $\mathrm{Pt}[23,24]$, the dopants of $\mathrm{Cu}$ and $\mathrm{Ag}$ typically produce a range of the dopant numbers in $\mathrm{M}_{\mathrm{x}} \mathrm{Au}_{25-\mathrm{x}}(\mathrm{SR})_{18}$ nanoclusters [15-17], but the total number of metal atoms is retained at 25 .

In this work we investigate the catalytic activities of the gold-based bimetallic $\mathrm{M}_{\mathrm{x}} \mathrm{Au}_{25-\mathrm{x}}(\mathrm{SR})_{18}$ 
nanoclusters (where, $\mathrm{M}=\mathrm{Ag}$ and $\mathrm{Au}$ ) in the oxidation of styrene using (diacetoxyiodo)benzene $\left(\mathrm{PhI}(\mathrm{OAc})_{2}\right)$ as the oxygen source. The $\mathrm{PhI}(\mathrm{OAc})_{2}$ oxidant is of low toxicity and is a very powerful oxygen atom donor in epoxidation reactions [25].

\section{Experimental}

\subsection{Synthesis and characterization of $M_{x} A u_{25-x}(S R)_{18}(M=C u, A g)$ and $A u_{25}(S R)_{18}$}

$\mathrm{Cu}_{\mathrm{x}} \mathrm{Au}_{25-\mathrm{x}}\left(\mathrm{SC}_{2} \mathrm{H}_{4} \mathrm{Ph}\right)_{18}, \mathrm{Ag}_{\mathrm{x}} \mathrm{Au}_{25-\mathrm{x}}\left(\mathrm{SC}_{2} \mathrm{H}_{4} \mathrm{Ph}\right)_{18}$, and $\mathrm{Au}_{25}\left(\mathrm{SC}_{2} \mathrm{H}_{4} \mathrm{Ph}\right)_{18}$ were synthesized according to modified methods [17,26]. The synthesis of $\mathrm{Au}_{25}\left(\mathrm{SC}_{2} \mathrm{H}_{4} \mathrm{Ph}\right)_{18}$ is as follows. Tetraoctylammonium bromide (TOABr, $101.5 \mathrm{mg})$ and $\mathrm{HAuCl}_{4} \cdot 4 \mathrm{H}_{2} \mathrm{O}(60.9 \mathrm{mg})$ were dissolved in THF $(10.0 \mathrm{~mL})$ in a three-necked flask. $\mathrm{PhCH}_{2} \mathrm{CH}_{2} \mathrm{SH}(106 \mathrm{~mL})$ was slowly added to the flask. After the solution turned clear over a period of ca. $0.5 \mathrm{~h}$, an aqueous solution of $\mathrm{NaBH}_{4}(58.7 \mathrm{mg}$, freshly dissolved in $3.0 \mathrm{~mL}$ ice-cold nanopure water) was rapidly added at once under slow stirring. After ca. three hours, the reaction was stopped, and THF was removed by rotary evaporation. The black solids were collected and thoroughly washed with $\mathrm{MeOH}$, $\mathrm{Au}_{25}\left(\mathrm{SC}_{2} \mathrm{H}_{4} \mathrm{Ph}\right)_{18}$ was extracted by $\mathrm{MeCN}$, and charactized by matrix-assisted laser desorption ionization

mass spectrometry (MALDI-MS) analysis. The syntheses of $\mathrm{Cu}_{\mathrm{x}} \mathrm{Au}_{25-\mathrm{x}}\left(\mathrm{SC}_{2} \mathrm{H}_{4} \mathrm{Ph}\right)_{18}$ and $\mathrm{Ag}_{\mathrm{x}} \mathrm{Au}_{25-\mathrm{x}}\left(\mathrm{SC}_{2} \mathrm{H}_{4} \mathrm{Ph}\right)_{18}$ nanoclusters followed a similar procedure as above, except that copper(II) acetate and silver(I) acetate were added in a 1 to 10 copper-to-gold and silver-to-gold ratio.

\subsection{Characterization of cluster}

The UV-Vis spectra of the nanoclusters (dissolved in $\mathrm{CH}_{2} \mathrm{Cl}_{2}$ ) were acquired on a Hewlett-Packard (HP) Agilent 8453 diode array spectrophotometer at room temperature. Matrix-assisted laser desorption ionization (MALDI) mass spectrometry was performed with a PerSeptive Biosystems Voyager DE super-STR time-of-flight (TOF) mass spectrometer. Trans-2-[3-(4-tert-butylphenyl)-2-methyl-2propenyldidene]-malononitrile (DCTB) was used as the matrix in MALDI-MS analysis. Typically, $0.1 \mathrm{mg}$ matrix and $10 \mu \mathrm{L}$ analyte stock solution were mixed in $10 \mu \mathrm{L} \mathrm{CH}_{2} \mathrm{Cl}_{2}$, and the mixed solution was applied to the steel plate and then air-dried prior to MALDI analysis.

\subsection{Preparation of 1 wt\% $M_{x} A u_{25-x}(S R)_{18} /$ oxides $(M=C u, A g)$ and $1 w t \% A u_{25}(S R)_{18}$ /oxides}


Typically, $1 \mathrm{mg} \mathrm{M}_{\mathrm{x}} \mathrm{Au}_{25-\mathrm{x}}(\mathrm{SR})_{18}$ or $\mathrm{Au}_{25}(\mathrm{SR})_{18}$ clusters were dissolved in $5 \mathrm{ml} \mathrm{DCM}$, and $100 \mathrm{mg}$ oxides $\left(\mathrm{TiO}_{2}, \mathrm{CeO}_{2}\right.$ and $\left.\mathrm{SiO}_{2}\right)$ were added. After stirred $12 \mathrm{~h}$ at r.t., $\mathrm{M}_{\mathrm{x}} \mathrm{Au}_{25-\mathrm{x}}(\mathrm{SR})_{18} /$ oxides catalysts were collected by centrifugation and dried in vacuum. As shown in the high-resolution scanning transmission electronmicroscopy (STEM) image, the interplanar distance of the $\mathrm{TiO}_{2}$ support is $0.35 \mathrm{~nm}$ (Figure $\mathrm{S} 1$ in the Supporting Information), in agreement with the $\{101\}$ plane of the anatase phase of $\mathrm{TiO}_{2}$.

\subsection{Typical procedure for styrene oxidation}

In a typical reaction, $\mathrm{PhI}(\mathrm{OAc})_{2}(0.1 \mathrm{mmol})$, styrene $(0.1 \mathrm{mmol})$ and $1 \mathrm{wt} \%$ cluster/oxide catalysts (100 mg, pretreated at $150^{\circ} \mathrm{C}$ in vacuum for $2 \mathrm{~h}$ ) were mixed in $2 \mathrm{~mL}$ acetonitrile. The mixture was stirred under $\mathrm{N}_{2}$ atmosphere at $70{ }^{\circ} \mathrm{C}$ for $10 \mathrm{~h}$ as indicated in Table 1 . The product was obtained after removal of the solvent of the supernatant. The conversion of styrene and yields of styrene epoxide, benzaldehyde and acetophenone were determined by ${ }^{1} \mathrm{H}$ NMR $(300 \mathrm{MHz})$ spectroscopic analysis.

\section{Results and discussion}

\subsection{Characterization of clusters}

The three types of nanoclusters (i.e., multiple-atom doped $\mathrm{Cu}_{\mathrm{x}} \mathrm{Au}_{25-\mathrm{x}}(\mathrm{SR})_{18}(\mathrm{x}=0$ to 5) and $\mathrm{Ag}_{\mathrm{x}} \mathrm{Au}_{25-\mathrm{x}}(\mathrm{SR})_{18}(\mathrm{x}=4$ to 8$)$ [17], as well as homogold $\mathrm{Au}_{25}(\mathrm{SR})_{18}$ nanoclusters [26] were synthesized following the literature protocols. The nanoclusters were characterized by matrix-assisted laser desorption/ionization (MALDI) mass spectrum (Fig. 1). The MALDI mass spectrum of $\mathrm{Au}_{25}(\mathrm{SR})_{18}$ nanocluster exhibits a single intense peak at $\mathrm{m} / \mathrm{z} 7394(\mathrm{z}=1)$, consistent with the calculated formula weight of 7393.72 for $\mathrm{Au}_{25}(\mathrm{SR})_{18}$, where $\mathrm{R}=\mathrm{CH}_{2} \mathrm{CH}_{2} \mathrm{Ph}$ (Fig. 1A); of note, the small peak at 6057 is an inevitable fragment $\left(\mathrm{Au}_{21}(\mathrm{SR})_{14}\right)$ caused by the somewhat destructive MALDI method, i.e., laser irradiation caused the loss of a $\mathrm{Au}_{4}(\mathrm{SR})_{4}$ unit from the parent $\mathrm{Au}_{25}(\mathrm{SR})_{18}$ nanocluster, resulting in some $\mathrm{Au}_{21}(\mathrm{SR})_{14}$ fragments [26]. No other peaks were found, indicating the high purity of the $\mathrm{Au}_{25}(\mathrm{SR})_{18}$

nanoclusters. The cases of $\mathrm{Ag}$ and $\mathrm{Cu}$ doping gave rise to a range of $\mathrm{x}$ values for $\operatorname{Ag}_{\mathrm{x}} \mathrm{Au}_{25-\mathrm{x}}(\mathrm{SR})_{18}$ or $\mathrm{Cu}_{\mathrm{x}} \mathrm{Au}_{25-\mathrm{x}}(\mathrm{SR})_{18}$ (Fig. 1C-D), but the total number of metal atoms per cluster is preserved at 25, indicating the high stability of the 25-metal-atom structure [13]. As shown in Fig. 1C, the average spacing of the 
$\mathrm{Ag}_{\mathrm{x}} \mathrm{Au}_{25-\mathrm{x}}(\mathrm{SR})_{18}$ peaks is 89.5 , i.e. the atomic mass difference between gold and silver $\left(\mathrm{M}_{\mathrm{Au}}-\mathrm{M}_{\mathrm{Ag}}=\right.$ $197.0-107.9=89.1$, which suggests that gold atoms are successively replaced by silver atoms with the total number retained at 25. Similarly, in the case of $\mathrm{Cu}_{\mathrm{x}} \mathrm{Au}_{25-\mathrm{x}}(\mathrm{SR})_{18}$ (Fig. 1D), the average peak spacing is 133.8 (theoretical $\mathrm{M}_{\mathrm{Au}}-\mathrm{M}_{\mathrm{Cu}}=197.0-63.5=133.5$ ), which also indicates the substitution of copper for gold atoms; however, the maximum replacement in $\mathrm{Cu}_{\mathrm{x}} \mathrm{Au}_{25-\mathrm{x}}(\mathrm{SR})_{18}$ is only up to $\mathrm{x}=5$ and is less than the case of $\operatorname{Ag}_{x} A_{25-x}(S R)_{18}$ (where, $x$ up to 8), Fig. 1C-D (insets).
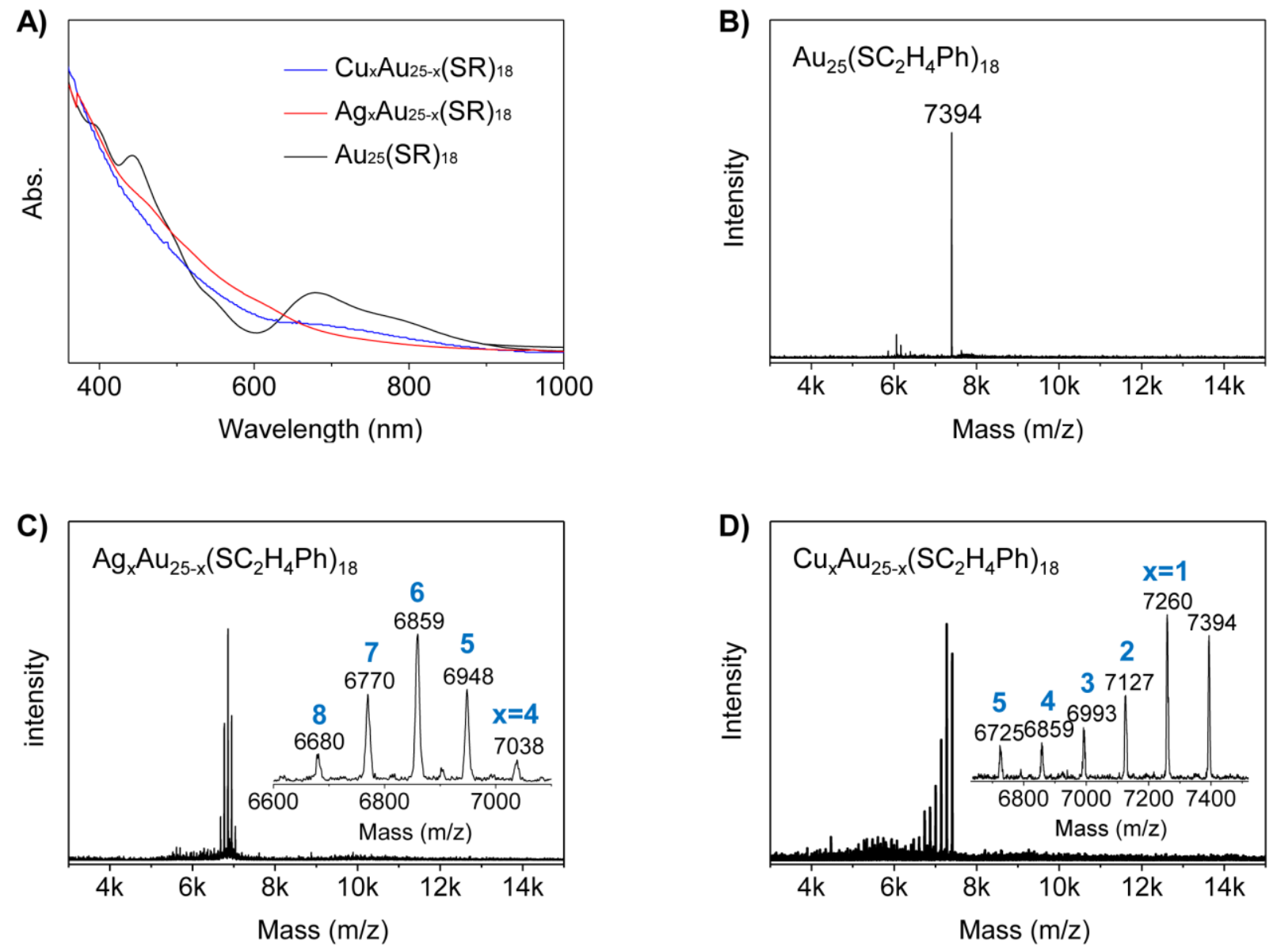

Fig. 1. (A) UV-vis spectra of $\mathrm{Au}_{25}(\mathrm{SR})_{18}$ and the doped nanoclusters, MALDI-MS of the (B) $\mathrm{Au}_{25}(\mathrm{SR})_{18},(\mathrm{C})$ $\mathrm{Ag}_{\mathrm{x}} \mathrm{Au}_{25-\mathrm{x}}(\mathrm{SR})_{18}(\mathrm{x}=4$ to 8$)$, and (D) $\mathrm{Cu}_{\mathrm{x}} \mathrm{Au}_{25-\mathrm{x}}(\mathrm{SR})_{18}(\mathrm{x}=0$ to 5). The insets in (C) and (D) are the zoom-in spectra. $\mathrm{R}=\mathrm{CH}_{2} \mathrm{CH}_{2} \mathrm{Ph}$. 


\subsection{Catalytic properties of $M_{x} A u_{25-x}(S R)_{18}(M=C u$, and $A g)$ and $A u_{25}(S R)_{18}$ clusters}

The $\mathrm{M}_{\mathrm{x}} \mathrm{Au}_{25-\mathrm{x}}(\mathrm{SR})_{18}(\mathrm{M}=\mathrm{Cu}$, and $\mathrm{Ag})$ and $\mathrm{Au}_{25}(\mathrm{SR})_{18}$ clusters were supported onto inorganic oxides (e.g. $\mathrm{TiO}_{2}, \mathrm{SiO}_{2}$, and $\mathrm{CeO}_{2}$ ) by impregnation of oxide powders in a dichloromethane (DCM) solution of clusters. The catalytic oxidation of styrene was performed in acetonitrile at $70{ }^{\circ} \mathrm{C}$ for $10 \mathrm{~h}$ under a $\mathrm{N}_{2}$ atmosphere, and other conditions are as follows: $0.1 \mathrm{mmol}$ styrene, $0.1 \mathrm{mmol} \mathrm{PhI}(\mathrm{OAc})_{2}, 100$ $\mathrm{mg}$ of $\mathrm{M}_{\mathrm{x}} \mathrm{Au}_{25-\mathrm{x}}(\mathrm{SR})_{18} /$ oxides (1 wt\% loading of ligated clusters). The conversion of styrene and the selectivities for benzaldehyde, styrene epoxide, and acetophenone were analyzed by ${ }^{1} \mathrm{H}$ NMR. In general, three products (styrene epoxide, benzaldehyde, and acetophenone) were yielded during the catalytic oxidation of styrene by gold nanoclusters (Scheme 1) [27-29]. A typical ${ }^{1} \mathrm{H}$ NMR spectrum is shown in Fig. S2. NMR analysis identified four components in the crude product: the residual styrene which shows signals at $\delta=\sim 5.25,5.75 \mathrm{ppm}\left(-\mathrm{C}=\mathrm{CH} \boldsymbol{H}_{2}\right)$, and $6.75 \mathrm{ppm}\left(\mathrm{Ph}-\boldsymbol{H C}=\mathrm{CH}_{2}\right)$, styrene epoxide at $\sim 2.83,3.18$ ppm $\left(\mathrm{PhCHOCH}_{2}\right)$ and $3.87 \mathrm{ppm}\left(\mathrm{PhCHOCH}_{2}\right)$, benzaldehyde at $10.02 \mathrm{ppm}(\mathrm{Ph}-\mathrm{CHO})$ and acetophenone at $2.56 \mathrm{ppm}\left(\mathrm{PhCOCH}_{3}\right)$. The phenyl groups of the four compounds and another side-product iodobenzene were overlapped from 7.0 to $8.2 \mathrm{ppm}$. The integrated peak areas and the $J-J$ coupling constants confirm the above assignment. By integrating and normalizing the NMR peak areas, the conversion and selectivity are calculated (averaged over three runs).

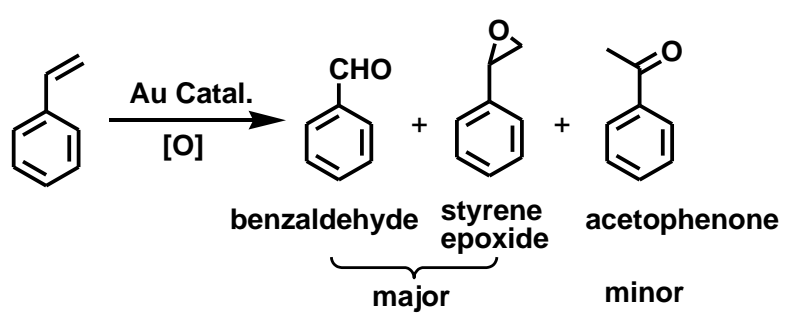

Scheme 1. Oxidation of styrene to yield styrene epoxide, benzaldehyde, and acetophenone.

We first compare the three types of clusters supported on $\mathrm{TiO}_{2}$. As shown in Table 1 (entries 1-4), the blank test (i.e. using plain $\mathrm{TiO}_{2}$ in the catalytic reaction) showed a $15.8 \%$ conversion of styrene, while the $\mathrm{Au}_{25}(\mathrm{SR})_{18} / \mathrm{TiO}_{2}$ catalyst showed a much higher conversion of styrene (58.9\%), indicating that gold 
clusters are essential in the styrene oxidation reaction. As to the product selectivity, the $\mathrm{Au}_{25}(\mathrm{SR})_{18} / \mathrm{TiO}_{2}$ catalyst gave a slightly higher selectivity for benzaldehyde (54\%) than styrene epoxide (44.3\%), with the remaining being acetophenone (1.7\%). After doping the gold cluster with silver, the catalytic activity is almost the same as that of $\mathrm{Au}_{25}(\mathrm{SR})_{18} / \mathrm{TiO}_{2}$, but the product selectivity for benzaldehyde is significantly increased (86.9\% over $\mathrm{Ag}_{\mathrm{x}} \mathrm{Au}_{25-\mathrm{x}}(\mathrm{SR})_{18} / \mathrm{TiO}_{2}$ vs $54.0 \%$ over $\left.\mathrm{Au}_{25}(\mathrm{SR})_{18} / \mathrm{TiO}_{2}\right)$. In contrast, the copper-doped clusters gave rise to a reduced activity (41.9\%) than that of the homogold catalyst, but the selectivity for the benzaldehyde product is higher (88.3\%). Overall, a distinct effect of doping is manifested in that both $\mathrm{Ag}$ and $\mathrm{Cu}$ doping enhance the product selectivity to benzaldehyde compared to the undoped cluster catalyst.

Table 1. Catalytic performance of cluster/oxide for styrene oxidation (treated in vacuum)

\begin{tabular}{|c|c|c|c|c|c|}
\hline \multirow[t]{2}{*}{ entry } & \multirow{2}{*}{ catalysts } & \multirow{2}{*}{$\begin{array}{c}\text { conversion } \\
\qquad \%)^{b}\end{array}$} & \multicolumn{3}{|c|}{ selectivity (\%) ${ }^{b}$} \\
\hline & & & 1 & 2 & 3 \\
\hline 1 & Only $\mathrm{TiO}_{2}$ & 15.8 & 76.1 & 23.9 & trace \\
\hline 2 & $\mathrm{Au}_{25}(\mathrm{SR})_{18} / \mathrm{TiO}_{2}$ & 58.9 & 54.0 & 44.3 & 1.7 \\
\hline 3 & $\mathrm{Ag}_{\mathrm{x}} \mathrm{Au}_{25-\mathrm{x}}(\mathrm{SR})_{18} / \mathrm{TiO}_{2}$ & 60.1 & 86.9 & 12.4 & 0.7 \\
\hline 4 & $\mathrm{Cu}_{\mathrm{x}} \mathrm{Au}_{25-\mathrm{x}}(\mathrm{SR})_{18} / \mathrm{TiO}_{2}$ & 41.9 & 88.3 & 11.7 & trace \\
\hline 5 & Only $\mathrm{CeO}_{2}$ & 14.1 & 53.2 & 46.8 & trace \\
\hline 6 & $\mathrm{Au}_{25}(\mathrm{SR})_{18} / \mathrm{CeO}_{2}$ & 64.2 & 46.7 & 51.9 & 1.4 \\
\hline 7 & $\mathrm{Ag}_{\mathrm{x}} \mathrm{Au}_{25-\mathrm{x}}(\mathrm{SR})_{18} / \mathrm{CeO}_{2}$ & 82.1 & 46.4 & 53.6 & trace \\
\hline 8 & $\mathrm{Cu}_{\mathrm{x}} \mathrm{Au}_{25-\mathrm{x}}(\mathrm{SR})_{18} / \mathrm{CeO}_{2}$ & 66.3 & 52.9 & 47.1 & trace \\
\hline 9 & Only $\mathrm{SiO}_{2}$ & 13.3 & 53.3 & 46.5 & trace \\
\hline 10 & $\mathrm{Au}_{25}(\mathrm{SR})_{18} / \mathrm{SiO}_{2}$ & 54.5 & 50.3 & 48.7 & 1.0 \\
\hline
\end{tabular}




$\begin{array}{llllll}11 & \mathrm{Ag}_{\mathrm{x}} \mathrm{Au}_{25-\mathrm{x}}(\mathrm{SR})_{18} / \mathrm{SiO}_{2} & 81.5 & 71.2 & 28.2 & 0.6 \\ 12 & \mathrm{Cu}_{\mathrm{x}} \mathrm{Au}_{25-\mathrm{x}}(\mathrm{SR})_{18} / \mathrm{SiO}_{2} & 65.7 & 74.9 & 24.4 & 0.7\end{array}$

[a] Reaction conditions: $0.1 \mathrm{mmol}$ styrene, $0.1 \mathrm{mmol} \mathrm{PhI}(\mathrm{OAc})_{2}, 100 \mathrm{mg} 1 \mathrm{wt} \%$ loading $\mathrm{M}_{\mathrm{x}} \mathrm{Au}_{25-\mathrm{x}}(\mathrm{SR})_{18} /$ oxides, 2 $\mathrm{mL}$ acetonitrile, $70{ }^{\circ} \mathrm{C}, 10 \mathrm{~h}$. [b] The conversion of styrene and the selectivities of benzaldehyde, styrene epoxide, and acetophenone were analyzed by ${ }^{1} \mathrm{H}$ NMR.

With respect to the $\mathrm{CeO}_{2}$-supported $\mathrm{M}_{\mathrm{x}} \mathrm{Au}_{25-\mathrm{x}}(\mathrm{SR})_{18}$ and $\mathrm{Au}_{25}(\mathrm{SR})_{18}$ catalysts (Table 1, entries 5-8), the $\mathrm{Ag}_{\mathrm{x}} \mathrm{Au}_{25-\mathrm{x}}(\mathrm{SR})_{18} / \mathrm{CeO}_{2}$ gave a much higher activity (82.1\% conversion of styrene) than other catalysts, while the product selectivities are almost the same as the case of the undoped catalyst. No distinct effect in both activity and selectivity was observed for the $\mathrm{Cu}$-doped catalyst.

In the case of $\mathrm{SiO}_{2}$-supported catalysts, we again observed that the Ag-doped catalyst gave a much higher activity and an increased selectivity for benzaldehyde compared to the undoped catalyst. Similarly, the $\mathrm{Cu}$-doped cluster offered a distinct increase in the selectivity for benzaldehyde but the increase in catalytic activity is less than that of the $\mathrm{Ag}_{\mathrm{x}} \mathrm{Au}_{25-\mathrm{x}}(\mathrm{SR})_{18} / \mathrm{SiO}_{2}$.

\subsection{Insights from the $M_{x} A u_{25-x}(S R)_{18}(M=C u, A g)$ and $A u_{25}(S R)_{18}$ cluster catalysts}

Based on the above catalytic results, the catalytic selectivity is affected by both the oxide support and the metal clusters. $\mathrm{TiO}_{2}$ prefers benzaldehyde while both $\mathrm{CeO}_{2}$ and $\mathrm{SiO}_{2}$ give rise to roughly equal benzaldehyde and styrene epoxide products. The activity of all of the three plain oxides is low (13.3 $15.8 \%)$.

The loading of $\mathrm{Au}_{25}(\mathrm{SR})_{18}$ clusters onto $\mathrm{TiO}_{2}, \mathrm{CeO}_{2}$ and $\mathrm{SiO}_{2}$ gave rise to roughly $50 \%$ selectivities for benzaldehyde and styrene epoxide. The $\mathrm{TiO}_{2}$-supported $\mathrm{M}_{\mathrm{x}} \mathrm{Au}_{25-\mathrm{x}}(\mathrm{SR})_{18}(\mathrm{M}=\mathrm{Ag}, \mathrm{Cu})$ catalysts prefer to yield benzaldehyde (Table 1, entries 3 and $4 ; 86.9 \%$ over $\operatorname{Ag}_{\mathrm{x}} \mathrm{Au}_{25-\mathrm{x}}(\mathrm{SR})_{18}, 88.3 \%$ over $\left.\mathrm{Cu}_{\mathrm{x}} \mathrm{Au}_{25-\mathrm{x}}(\mathrm{SR})_{18}\right)$. This trend is also consistent with the case of $\mathrm{Pt}_{1} \mathrm{Au}_{24}(\mathrm{SR})_{18}(89.9 \%$ selectivity for benzaldehye) [22]. In the case of $\mathrm{CeO}_{2}$-supported $\mathrm{M}_{\mathrm{x}} \mathrm{Au}_{25-\mathrm{x}}(\mathrm{SR})_{18}$ catalysts, no major difference in the selectivities for benzaldehyde and styrene epoxide is found, indicating a cooperative role of the cluster and the support in affecting the product selectivities, which is reminiscent of the cluster/support interfacial effect, either in terms of charge transfer or the perimeter sites of the interface being the 
catalytically active centers. Further insight can be obtained from the case of the catalytic selectivity of $\mathrm{SiO}_{2}$-supported $\mathrm{M}_{\mathrm{x}} \mathrm{Au}_{25-\mathrm{x}}(\mathrm{SR})_{18}$ catalysts, in which both $\mathrm{Ag}$ - and $\mathrm{Cu}$-doped $\mathrm{M}_{\mathrm{x}} \mathrm{Au}_{25-\mathrm{x}}(\mathrm{SR})_{18}$ nanoclusters offer distinctly enhanced selectivity for benzaldehyde (Table 1, entries 10-12). It is well known that $\mathrm{SiO}_{2}$ is chemically inert and does not exhibit any charge transfer to or from the cluster, thus, we rationalize that the perimeter sites of the cluster/support interface should be the catalytically active centers, which can explain the cooperative role of the cluster and the support in tuning the selectivity for product.

With respect to the atomic structure of $\mathrm{M}_{\mathrm{x}} \mathrm{Au}_{25-\mathrm{x}}(\mathrm{SR})_{18}(\mathrm{M}=\mathrm{Ag}, \mathrm{Cu})$, both types of dopants were confirmed to reside at the icosahedral surface $[15,16]$, in contrast with the case of Pt doping in which the single Pt atom is located in the icosahedral center [22]. Thus, the above catalytic results indicate that the selectivities for benzaldehyde and styrene epoxide are also affected by the inner icosahedral shell of the $\mathrm{M}_{\mathrm{x}} \mathrm{Au}_{25-\mathrm{x}}(\mathrm{SR})_{18}$ (both $\mathrm{Ag}$ and $\mathrm{Cu}$ doping). This insight is in contrast with the previously reported effect of central doping of a single $\mathrm{Pt}$ atom in $\mathrm{Pt}_{1} \mathrm{Au}_{24}(\mathrm{SR})_{18}$ for catalytic oxidation of styrene [22].

It has been reported in the literature [21] that the surface thiolate groups on gold nanoclusters can be partially oxidized by oxidants (e.g. $\mathrm{PhIO}$, which is similar to $\mathrm{PhI}(\mathrm{OAc})_{2}$ in our present work), and that the oxidized thiolates (e.g. in the form of sulfoxide) are eliminated from the cluster surface to generate unprotected gold surface. To test that, we performed IR measurements on the $\mathrm{Au}_{25}(\mathrm{SR})_{18}$ and $\mathrm{Ag}_{\mathrm{x}} \mathrm{Au}_{25-\mathrm{x}}(\mathrm{SR})_{18}$ catalysts after treatment with $\mathrm{PhI}(\mathrm{OAc})_{2}$ (Fig. 2). The fresh $\mathrm{Au}_{25}\left(\mathrm{SCH}_{2} \mathrm{CH}_{2} \mathrm{Ph}\right)_{18} / \mathrm{TiO}_{2}$ catalyst shows IR absorption bands at 2860, 2930 and $2960 \mathrm{~cm}^{-1}$, which are from the aliphatic C-H stretching vibration of the $-\mathrm{SCH}_{2} \mathrm{CH}_{2} \mathrm{Ph}$ ligands. Treatment with $\mathrm{PhI}(\mathrm{OAc})_{2}$ at room temperature or $70{ }^{\circ} \mathrm{C}$ did not lead to significant changes except that the $2860 \mathrm{~cm}^{-1}$ band became somewhat weaker (Fig. 2A). A similar result was also observed in the case of $\mathrm{Ag}_{x} \mathrm{Au}_{25-\mathrm{x}}\left(\mathrm{SCH}_{2} \mathrm{CH}_{2} \mathrm{Ph}\right)_{18} / \mathrm{TiO}_{2}$ catalyst (Fig. 2B). Thus, the clusters are quite stable under the oxidation conditions; nevertheless, the IR results do not rule out the possibility that some ligands might be stripped off during the prolonged reaction process. 

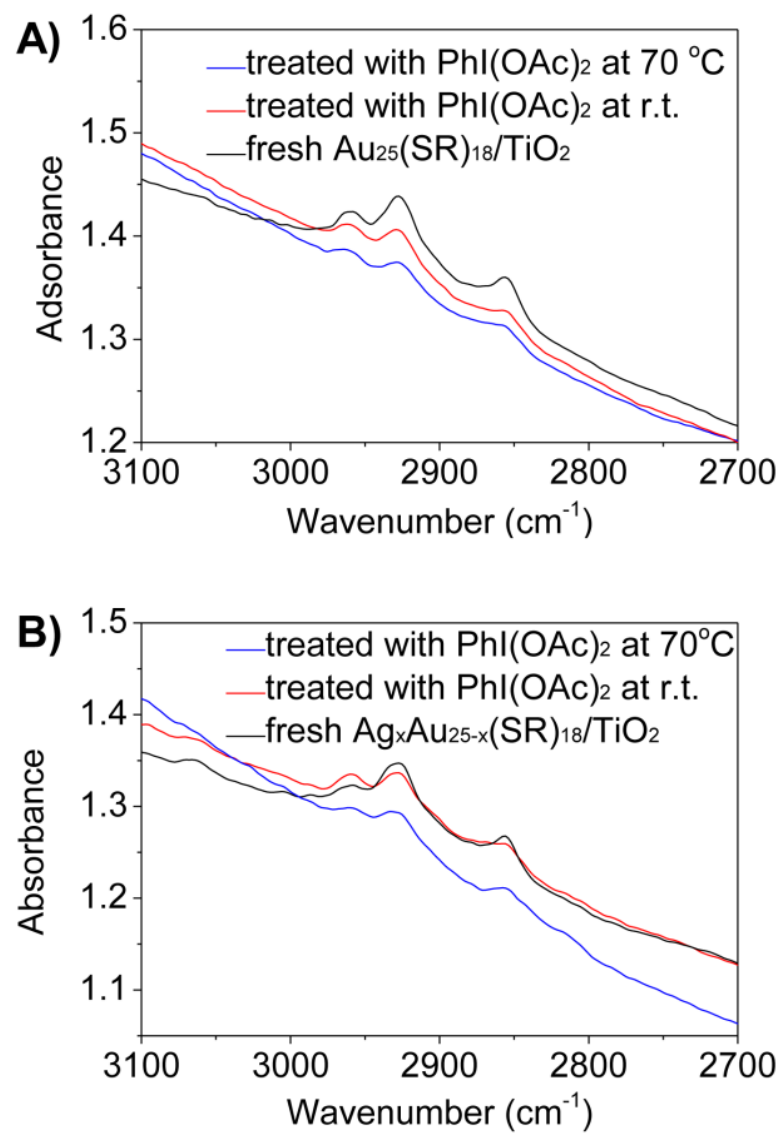

Fig. 2. IR spectra of (A) the $\mathrm{Au}_{25}\left(\mathrm{SCH}_{2} \mathrm{CH}_{2} \mathrm{Ph}\right)_{18} / \mathrm{TiO}_{2}$ and (B) $\mathrm{Ag}_{\mathrm{x}} \mathrm{Au}_{25-\mathrm{x}}\left(\mathrm{SCH}_{2} \mathrm{CH}_{2} \mathrm{Ph}\right)_{18} / \mathrm{TiO}_{2}$ catalysts after different treatments.

Spectroscopic evidence for the absorption of alkene on gold nanoclusters during epoxidation was reported in the literature [30]. Experimental and theoretical studies of the catalytic activity of bare gold clusters $\left(\mathrm{Au}_{6-10}\right)$ [31], as well as model calculations on the oxidation over $\mathrm{Au}(111)$ surfaces [32], have also been reported. The role of the support in the oxidation has been studied in the literature [33,34]. Based on the literature and our own results discussed above, we propose a possible catalytic mechanism for the styrene oxidation reaction. First, the cluster/support interface should be the catalytic sites. The ligated clusters or the partially dethiolated clusters adsorb the reactants. The reactant styrene should be absorbed on the gold/support surface, and $\mathrm{PhI}(\mathrm{OAc})_{2}$ to be activated through weak $\mathrm{Au} \cdots \mathrm{O}$ interaction with the gold surface [21], then oxygen-atom transfers to styrene to yield benzaldehyde and styrene epoxide (Scheme 2). Given the location of $\mathrm{Ag}$ (or $\mathrm{Cu}$ atoms) at the inner icosaheral surface [35] (Scheme 2, right 
panel), after partial dethiolation there is a possibility that the $\mathrm{Ag}$ (or $\mathrm{Cu}$ ) atoms may migrate from the inner icosahedral surface to the outer surface and exchange atomic sites with surface gold, but this chance should be less and future analysis by X-ray absorption spectroscopy [36] may provide further information.

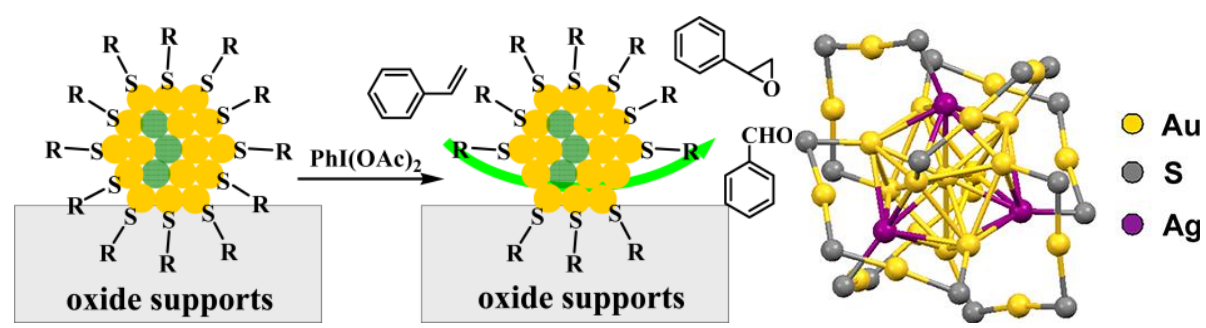

Scheme 2. Schematic illustration of a possible catalytic mechanism of oxidation of styrene catalyzed by gold nanoclusters with $\mathrm{PhI}(\mathrm{OAc})_{2}$ as the oxidant. The right panel shows the low-energy configuration of $\mathrm{Ag}_{3} \mathrm{Au}_{22}(\mathrm{SR})_{18}$ (the $\mathrm{R}$ groups are omitted in the drawing) [35].

\section{Conclusion}

In summary, we have investigated the catalytic properties of copper or silver-doped bimetallic $\mathrm{M}_{\mathrm{x}} \mathrm{Au}_{25-\mathrm{x}}(\mathrm{SR})_{18}$ nanocluster catalysts in the selective oxidation of styrene using (diacetoxyiodo)benzene as the oxidant. Both $\operatorname{Ag}_{\mathrm{x}} \mathrm{Au}_{25-\mathrm{x}}(\mathrm{SR})_{18}$ and $\mathrm{Cu}_{\mathrm{x}} \mathrm{Au}_{25-\mathrm{x}}(\mathrm{SR})_{18}$ clusters increase the product selectivity toward benzaldehyde. The results indicate that the selectivities for benzaldehyde and styrene epoxide are affected by the inner shell of the icosahedral $\mathrm{M}_{\mathrm{x}} \mathrm{Au}_{25-\mathrm{x}}(\mathrm{SR})_{18}$ clusters. The atomic level insights into the factors influencing the catalytic activity and selectivity will be useful in mapping out the detailed catalytic mechanism and the new design of selective catalysts.

Acknowledgement: This work is based on the financial support by the U.S. National Science Foundation (DMR-0903225).

\section{References}

[1] C.L. Bracey, P.R. Ellis, G.J. Hutchings, Application of copper-gold alloys in catalysis: current status and future perspectives, Chem. Soc. Rev. 38 (2009) 2231-2243.

[2] C.D. Pina, E. Falletta, L. Prati, M. Rossi, Selective oxidation using gold, Chem. Soc. Rev. 37 (2008) 2077-2095.

[3] A. Corma, H. Garcia, Supported gold nanoparticles as catalysts for organic reactions, Chem. Soc. Rev. 37 (2008) 2096-2126. 
[4] M.D. Hughes, Y.J. Xu, P. Jenkins, P. McMorn, P. Landon, D.I. Enache, A.F. Carley, G.A. Attard, G.J. Hutchings, F. King, E.H. Stitt, P. Johnston, K. Griffin, C.J. Kiely, Tunable gold catalysts for selective hydrocarbon oxidation under mild conditions, Nature 437 (2005) 1132-1135.

[5] X. Nie, H. Qian, Q. Ge, H. Xu, R. Jin, CO oxidation catalyzed by oxide-supported $\mathrm{Au}_{25}(\mathrm{SR})_{18}$ nanoclusters and identification of perimeter sites as active centers. ACS Nano 6 (2012) 6014-6022.

[6] R.P. Doherty, J.M. Krafft, C. Méthivier, S. Casale, H. Remita, C. Louis, C. Thomas, On the promoting effect of $\mathrm{Au}$ on $\mathrm{CO}$ oxidation kinetics of Au-Pt bimetallic nanoparticles supported on $\mathrm{SiO}_{2}$ : An electronic effect? J. Catal. 287 (2012) 102-113.

[7] C.D. Pina, E. Falletta, M. Rossi, Highly selective oxidation of benzyl alcohol to benzaldehyde catalyzed by bimetallic gold-copper catalyst, J. Catal. 260 (2008) 384-386.

[8] N.K. Chaki, H. Tsunoyama, Y. Negishi, H. Sakurai, T. Tsukuda, Effect of Ag-doping on the catalytic activity of polymer-stabilized Au clusters in aerobic oxidation of alcohol, J. Phys. Chem. C 111 (2007) 4885-4888.

[9] D. Wang, A. Villa, P. Spontoni, D.S. Su, L. Prati, In situ formation of Au-Pd bimetallic active sites promoting the physically mixed monometallic catalysts in the liquid-phase oxidation of alcohols, Chem. Eur. J. 16 (2010) 10007-10013.

[10] J. Llorca, M. Dominguez, C. Ledesma, R.J. Chimentao, F. Medina, J. Sueiras, I. Angurell, M. Seco, O. Rossell, Propene epoxidation over $\mathrm{TiO}_{2}$-supported $\mathrm{Au}$-Cu alloy catalysts prepared from thiol-capped nanoparticles, J. Catal. 258 (2008) 187-198.

[11] Y. Zhu, H. Qian, R. Jin, An atomic-level strategy for unraveling gold nanocatalysis from the perspective of $\mathrm{Au}_{n}(\mathrm{SR})_{m}$ nanoclusters, Chem. Eur. J. 16 (2010) 11455-11462.

[12] Y. Liu, H. Tsunoyama, T. Akita, T. Tsukuda, Efficient and selective epoxidation of styrene with TBHP catalyzed by $\mathrm{Au}_{25}$ clusters on hydroxyapatite, Chem. Commun. 46 (2010) 550-552.

[13] G. Li, R. Jin, Atomically Precise Gold Nanoclusters as New Model Catalysts, Acc. Chem. Res. 46 (2013) 1749-1758.

[14] R. Jin and K. Nobusada, Doping and alloying in atomically precise gold nanoparticles, Nano Res. 7 (2014) $285-300$.

[15] Y. Negishi, T. Iwai, M. Ide, Continuous modulation of electronic structure of stable thiolate-protected $\mathrm{Au}_{25}$ cluster by Ag doping, Chem. Commun. 46 (2010) 4713-4715.

[16] Y. Negishi, K. Munakata, W. Ohgake, K. Nobusada, Effect of copper doping on electronic structure, geometric structure, and stability of thiolate-protected $\mathrm{Au}_{25}$ nanoclusters, J. Phys. Chem. Lett. 3 (2012) 2209-2214.

[17] E. Gottlieb, H. Qian, R. Jin, Chem. Eur. J. Atomic-level alloying and de-alloying in doped gold nanoparticles, 19 (2013) 4238-4243.

[18] S. Xie, H. Tsunoyama, W. Kurashige, Y. Negishi, T. Tsukuda, Enhancement in aerobic alcohol oxidation catalysis of $\mathrm{Au}_{25}$ clusters by single Pd atom doping, ACS Catal. 2 (2012) 1519-1523.

[19] T. Hayashi, K. Tanaka, M. Haruta, Selective vapor-phase epoxidation of propylene over $\mathrm{Au} / \mathrm{TiO}_{2}$ catalysts in the presence of oxygen and hydrogen, J. Catal. 178 (1998) 566-575.

[20] N. Dimitratos, A. Villa, D. Wang, F. Porta, D. Su, L. Prati, Pd and Pt catalysts modified by alloying with Au in the selective oxidation of alcohols, J. Catal. 244 (2006) 113-121.

[21] Y. Murakami, K. Konishi, Remarkable co-catalyst effect of gold nanoclusters on olefin oxidation catalyzed by a manganese-porphyrin complex, J. Am. Chem. Soc. 129 (2007) 14401-14407.

[22] H. Qian, D. Jiang, G. Li, C. Gayathri, A. Das, R.R. Gil, R. Jin, Monoplatinum doping of gold nanoclusters and 
catalytic application, J. Am. Chem. Soc. 134 (2012) 16159-16162.

[23] Y. Negishi, W. Kurashige, Y. Niihori, T. Iwasa, K. Nobusada, Isolation, structure, and stability of a dodecanethiolate-protected $\mathrm{Pd}_{1} \mathrm{Au}_{24}$ cluster, Phys. Chem. Chem. Phys. 12 (2010) 6219-6225.

[24] H. Qian, E. Barry, Y. Zhu, R. Jin, Doping 25-atom and 38-atom gold nanoclusters with palladium, Acta. Phys. Chim. Sin. 27 (2011) 513-519.

[25] J. Seayad, A.M. Seayad, C.L.L. Chai, Copper-catalyzed diacetoxylation of olefins using $\mathrm{PhI}(\mathrm{OAc})_{2}$ as Oxidant, Org. Lett. 12 (2010) 1412-1415.

[26] Z. Wu, J. Suhan, R. Jin, One-pot synthesis of atomically monodisperse, thiol-functionalized $\mathrm{Au}_{25}$ nanoclusters, J. Mater. Chem. 19 (2009) 622-626.

[27] J. Liu, K.S. Krishna, Y.B. Losovyj, S. Chattopadhyay, N. Lozova, J.T. Miller, J.J. Spivey, C.S.S.R. Kumar, Ligand-stabilized and atomically precise gold nanocluster catalysis: A case study for correlating fundamental electronic properties with catalysis, Chem. Eur. J. 19 (2013) 10201-10208.

[28] Y. Zhu, H. Qian, A. Das, R. Jin, Comparison of the catalytic properties of 25-atom gold nanospheres and nanorods, Chin. J. Catal. 32 (2011) 1149-1155.

[29] P. Huang, G. Chen, Z. Jiang, R. Jin, Y. Zhu, Y. Sun, Atomically precise $\mathrm{Au}_{25}$ superatoms immobilized on $\mathrm{CeO}_{2}$ nanorods for styrene oxidation, Nanoscale 5 (2013) 3668-3672.

[30] T.A. Nijhuis, E. Sacaliuc, A.M. Bealeb, A.M.J. van der Eerden, J.C. Schouten, B.M. Weckhuysen, Spectroscopic evidence for the adsorption of propene on gold nanoparticles during the hydro-epoxidation of propene, J. Catal. 258 (2008) 256-264.

[31] S. Lee, L.M. Molina, M.J. López, J.A. Alonso, B. Hammer, B. Lee, S. Seifert, R.E. Winans, J.W. Elam, M.J. Pellin, S. Vajda, Selective propene epoxidation on immobilized $\mathrm{Au}_{6-10}$ Clusters: The effect of hydrogen and water on activity and selectivity, Angew. Chem. Int. Ed. 48 (2009) 1467-1471.

[32] A. Roldan, D. Torres, J.M. Ricart, F. Illas, On the effectiveness of partial oxidation of propylene by gold: A density functional theory study, J. Mol. Catal. A: Chem. 306 (2009) 6-10.

[33] T.A. Nijhuis, E. Sacaliuc-Parvulescu, N.S. Govender, J.C. Schouten, B.M.M. Weckhuysen, The role of support oxygen in the epoxidation of propene over gold-titania catalysts investigated by isotopic transient kinetics, J. Catal. 265 (2009) 161-169.

[34] J. Fang, J. Li, B. Zhang, X. Yuan, H. Asakura, T. Tanaka, K. Teramura, J. Xie, N. Yan, The support effect on the size and catalytic activity of thiolated $\mathrm{Au}_{25}$ nanoclusters as precatalysts, Nanoscale 7 (2015) 6325-6333.

[35] D. R. Kauffman, D. Alfonso, C. Matranga, H. Qian, R. Jin, A Quantum Alloy: the Ligand-Protected $\mathrm{Au}_{22} \mathrm{Ag}_{3}(\mathrm{SR})_{18}$ Cluster, J. Phys. Chem. C 117 (2013) 7914-7923.

[36] P. Zhang, X-ray Spectroscopy of Gold-Thiolate Nanoclusters, J. Phys. Chem. C 118 (2014) 25291-25299. 
Graphical Abstract:

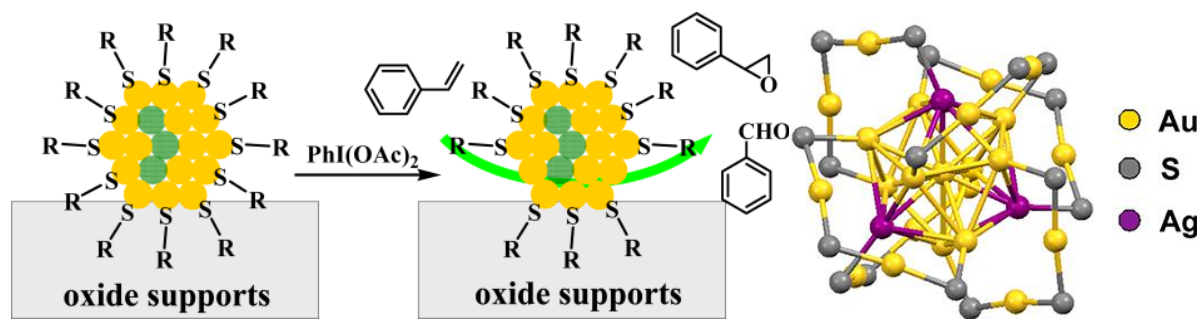

